\title{
Thermal Design Considerations of the Robotic Refueling Mission (RRM)
}

\author{
Teri H. Gregory ${ }^{1}$ \\ NASA Goddard Space Flight Center, Greenbelt, MD, 20771 \\ Miles Newman ${ }^{2}$ \\ ATK Space, Beltsville, MD, 20705
}

\begin{abstract}
The Robotic Refueling Mission (RRM) is a flight demonstration of the tasks required to perform robotic refueling of orbiting spacecraft. RRM will be mounted to an ExPress Adapter Plate (ExPA) for launch and installed onto the International Space Station (ISS) Express Logistics Carrier 4 (ELC4). RRM operations will be conducted using the Special Purpose Dexterous Manipulator (SPDM) robotic arm on the ISS with the ORU/Tool Changeout Mechanism (OTCM) for grasping tools and completing the refueling demonstration tasks. This paper presents the thermal considerations and design of the RRM including the tools required for the tasks.
\end{abstract}

\section{Introduction}

$\mathrm{R}$ RM will launch to the ISS on the last space shuttle flight, STS-135, and will be transported from the shuttle payload bay onto the SPDM Enhanced ORU Temporary Platform (EOTP) by an Extra Vehicular Activity (EVA) crew member. The Space Station Remote Manipulator System (SSRMS) will then use the SPDM to relocate RRM from the EOTP to its final location on the nadir facing ELC4. Figure 1 shows the SSRMS and SPDM installing RRM onto ELC4.

After installation onto ELC4, the RRM robotic tasks include acquiring and disassembling typical spacecraft fill/drain valve closeouts. This task includes cutting the safety wire and removing the cap, as well as actuating the valve and transferring fluid across the spacecraft fill/drain interface. In addition, the RRM will use the SPDM to demonstrate the manipulation and cutting of multilayer insulation (MLI) typically used to cover spacecraft fill/drain valves, the operation of typical door latches, and the mechanical

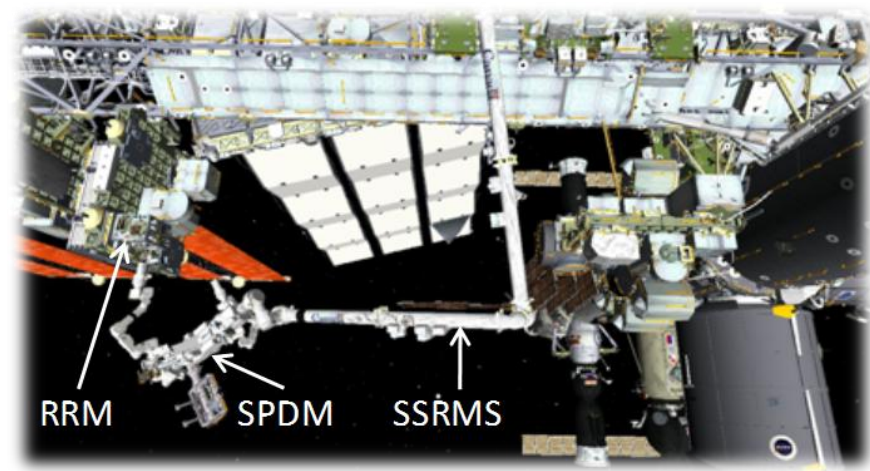

Figure 1. RRM installation onto ISS ELC4. manipulation of valves on a dummy Coolant Valve Panel (CVP) task board.

In order to accomplish these refueling tasks, the RRM will include four new robotic tools: the Wire Cutter Tool (WCT), the Safety Cap Tool (SCT), the Extra Vehicular Robotic (EVR) Nozzle Tool (ENT), and the Multi-function Tool (MFT). The ENT is used to transfer fluid across the spacecraft fill/drain valve interface. The WCT and SCT are used to demonstrate preparing a spacecraft fill/drain valve for refueling. The MFT provides an interface to four adapters. The Tertiary Cap Adapter will accommodate tertiary cap removal for the refueling task. The T-Valve adapter interfaces with a dummy T-Valve coolant line. The Ambient Cap Adapter and the Plug Manipulator Adapter will demonstrate mechanical manipulation of the other features on the RRM CVP.

${ }^{1}$ RRM Thermal Systems Lead, GSFC Thermal Engineering Branch (Code 545), 8800 Greenbelt Road, Greenbelt, MD. 20771.

${ }^{2}$ ATK Thermal Engineering Group Manager, ATK Spacecraft Systems, 5050 Powder Mill Road, Beltsville, MD. 20705. 


\section{RRM Overview}

The major RRM features include the Fluid Transfer System (FTS), two task boards, a CVP, tool adapters, and the four robotic tools required to accomplish the refueling demonstration and manipulate the features of the task boards and CVP. As shown in Figure 2, the task boards, CVP, and adapter receptacles are mounted externally onto the RRM enclosure.

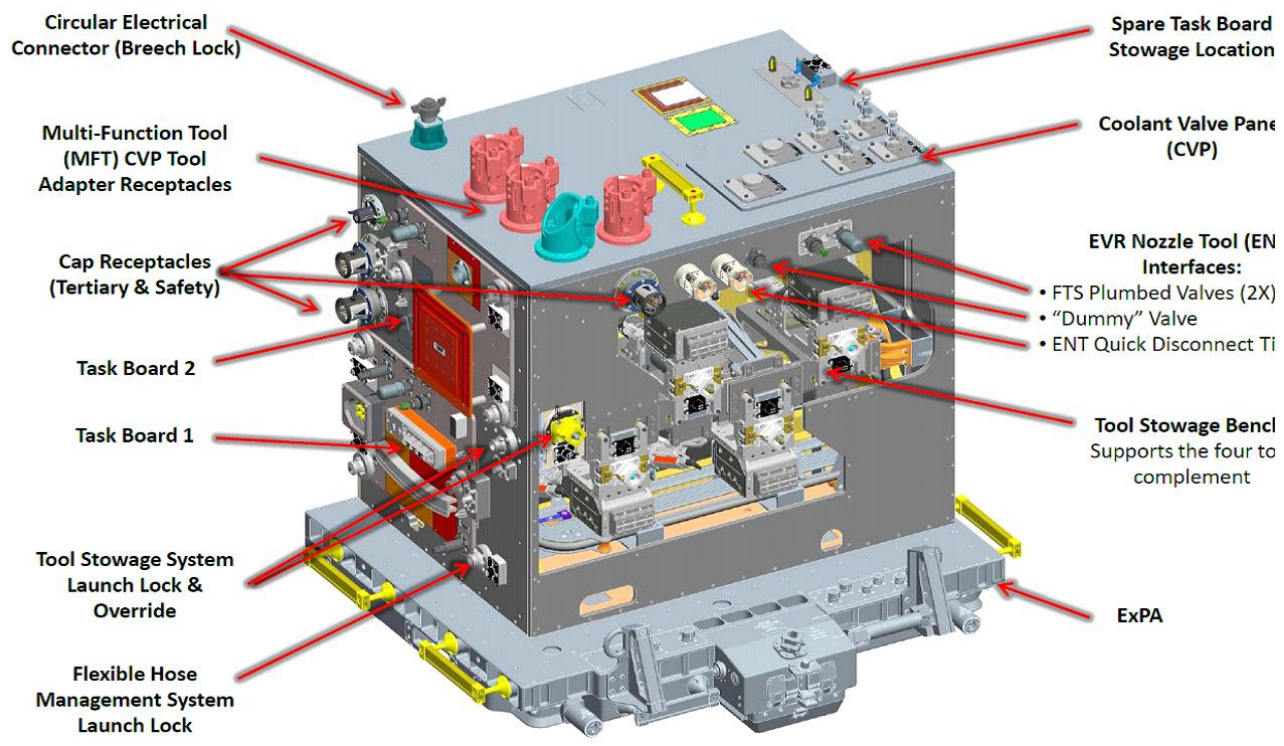

Figure 2. RRM external components.

The robotic tools are stowed on the tool stowage bench inside a recess on the front side of the RRM with their robotic interface microfixtures facing out. For operation, the SPDM grasps the tool's microfixture and pulls the tool out of the RRM tool stowage bench. After the operation is complete, SPDM restows the tool into its slot on the tool stowage bench.

\section{A. Fluid Transfer System}

The FTS is a loop system designed to demonstrate robotic on-orbit satellite refueling by transferring fluid across a typical spacecraft fill/drain valve. Since RRM will be launched aboard a space shuttle and installed onto ISS, manned spaceflight safety regulations require the use of a fluid other than hydrazine. For RRM, ethanol is used as the working fluid in place of hydrazine.

Figure 3 shows the FTS plate with his main components. The FTS provides the pumps and plumbing required to demonstrate a propellant transfer of fluid including monitoring devices, such as pressure transducers and thermistors, and controllable valves.

The FTS lines are then fed through the FTS plate and connected to fully functioning fill/drain valves and to the Flex Hose Management System for connection to the ENT through a flexible hose. A flexible hose and pulley system allows the tool to be removed from the tool stowage bench and installed onto the plumbed fill/drain valve for fluid transfer. Installing the ENT onto the plumbed fill/drain valve completes the loop to allow fluid transfer in a closed system.

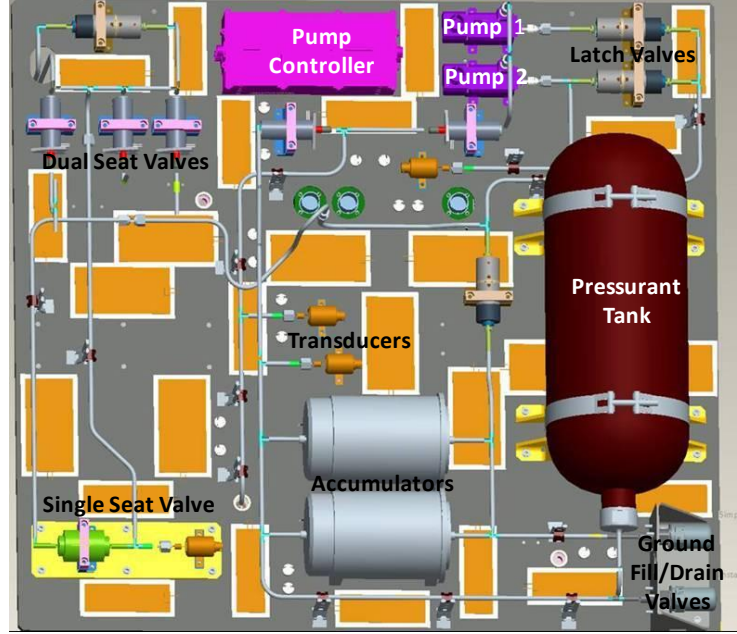

Figure 3. FTS Plate Front Face Components 
The Avionics Control Unit (ACU) is also located on the back of the FTS plate. The ACU uses discreet inputs to generate commands which control the valves and pump controllers. Figure 4 shows the back of the FTS plate with the fluid line locations to the valves and flexible hose and the location of the ACU.
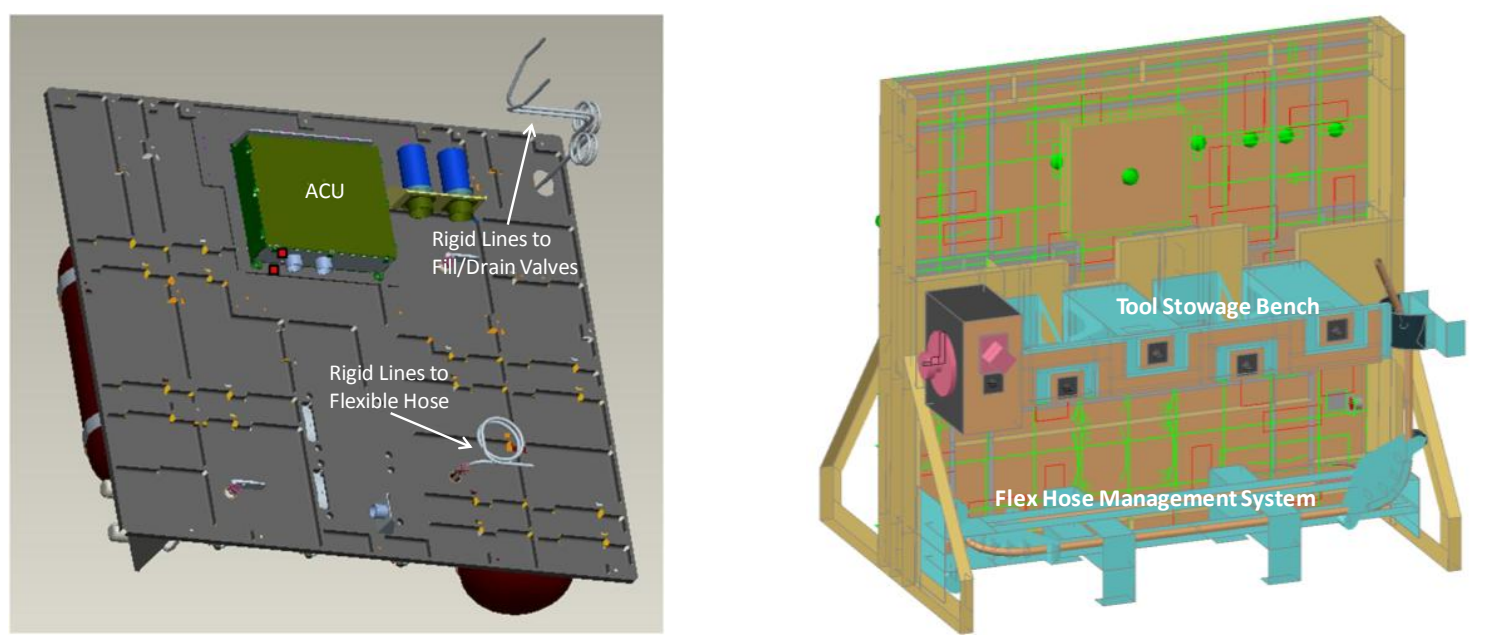

Figure 4. FTS Plate Back

\section{B. Task Board \#1}

Two task boards are mounted onto the external left face of RRM. These task boards provide work sites for additional tasks required for on-orbit robotic satellite servicing.

Figure 5 shows the components located on task board \#1. As the figure illustrates, task board \#1 contains mechanical and visual tasks designed to demonstrate robotic servicing. A dummy safety cap, tertiary cap, and nine SMA caps are included for robotic mechanical manipulation. In this case, the safety cap and tertiary cap are mounted without their wires as an opportunity to demonstrate cap removal even if the WCT cannot cut the wires on the other RRM safety and tertiary caps. Task board \#1 also contains a Marman clamp with three combinations of background colors to test the visual ability of the robot to interface and clamp onto the fixture under varying background contrasts.

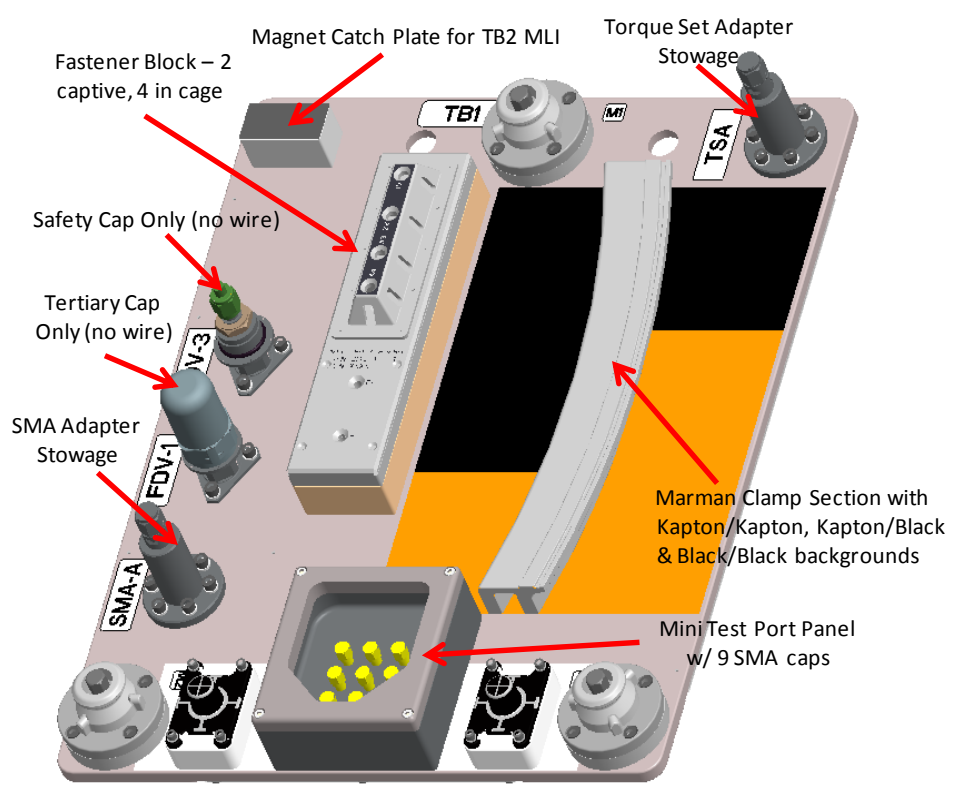

Figure 5. RRM Task Board \#1

\section{Task Board \#2}

Task board \#2 includes a tertiary cap and a safety cap, including their wires, to demonstrate robotically cutting the safety wire and removing each cap. These components are dummy caps which are not plumbed into the FTS. Task board \#2 also includes a test port panel for manipulating MLI and three robotic vision tasks. An explosive bolt hole simulation, an HST J-hook, and an HST door latch provide visual tests for the robotic interface. Figure 6 shows the major components on task board \#2 and Figure 7 shows the flight task boards mounted onto RRM. 


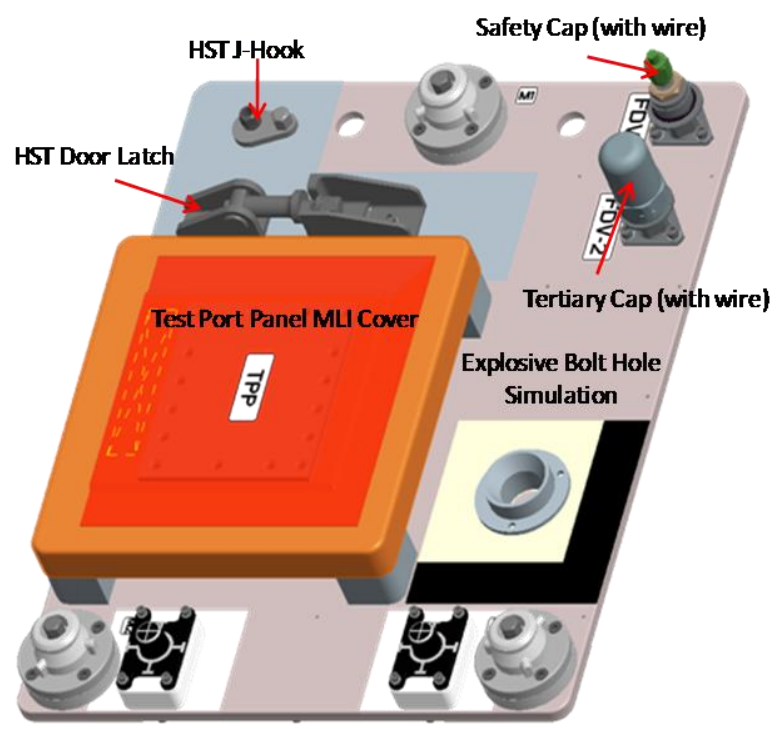

Figure 6. RRM Task Board \#2

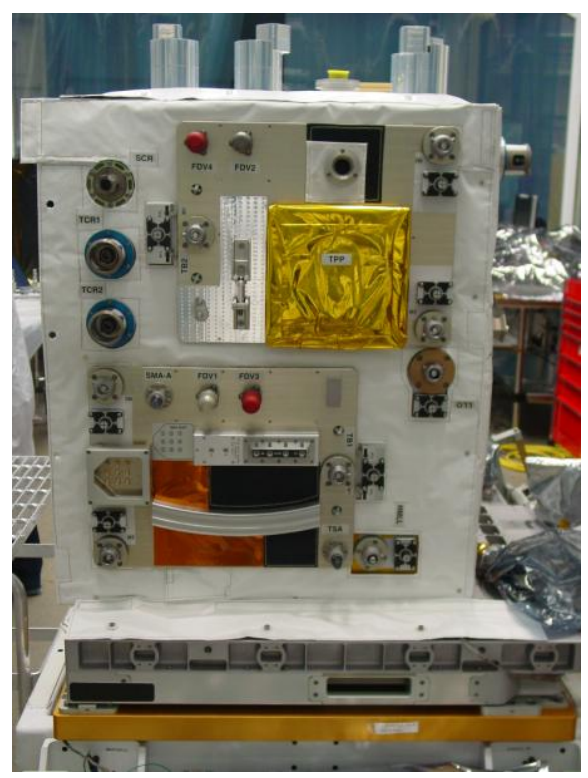

Figure 7. Flight Task Boards on RRM

\section{Coolant Valve Panel}

The CVP is mounted to the top surface of RRM and contains two ambient valves and four $\mathrm{T}$ valves for demonstrating robotic capture, rotate, removal, and stowage of the ambient cap and $T$ valve. The ambient valves terminate just below the CVP plate whereas the $T$ valves are attached to rigid lines that penetrate the RRM structure by approximately 4 inches. The $\mathrm{T}$ valve design will allow a robot to insert a bayonet into the coolant line in a future mission, if required. The surface coatings and silver teflon tape on the CVP are designed to match a typical flight configuration in order to verify successful operations under flight lighting conditions. Figure 8 shows the flight CVP mounted onto the RRM.

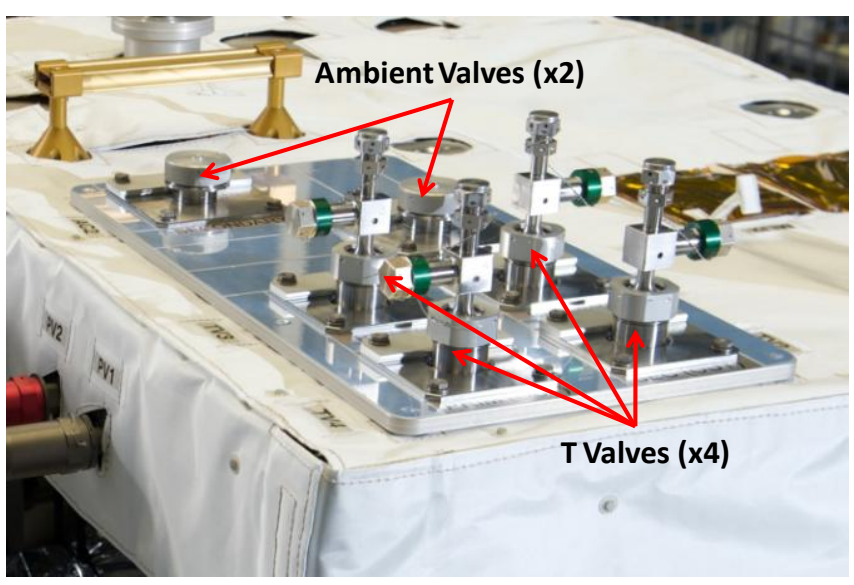

Figure 8. Flight CVP on RRM

\section{E. Robotic Tools}

In order to successfully refuel an orbiting spacecraft, the satellite's fill/drain valve must be exposed by cutting

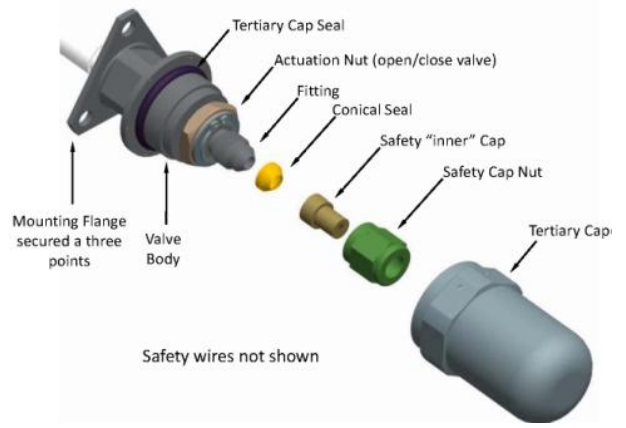

Figure 9. Typical Spacecraft Fill/Drain Valve Components and manipulating its closeout MLI and the tertiary and safety caps must be removed with their corresponding safety wires cut. Figure 9 shows the components of a typical spacecraft fill/drain valve.

For RRM, four robotic tools have been developed to complete the RRM satellite servicing demonstrations: the WCT, the MFT, the SCT, and the ENT. Each tool is equipped with two cameras to provide visual feedback to the telerobotic operator on the ground and a Tool Electronics Box (TEB). The TEB provides $15 \mathrm{~V}$ regulated power to the cameras, provides constant current power for four strings of LEDs for lighting, selects one of the two cameras for video 
downlink, and provides power to the survival heaters on the cameras and TEB. All four tools also utilize a universal central structure, called the Tool and Vision Support Structure (TVSS), that provides common stowage, electrical, and vision interfaces.

In order to expose a fill/drain valve, the WCT is used to cut away the closeout MLI. This task will be demonstrated on the MLI attached to task board \#2. In addition, the WCT is designed to cut the fill/drain valve safety wires as shown on the safety and tertiary caps on task board \#2.

The MFT provides a common interface with four adapters designed to accomplish four separate tasks. The MFT and Tertiary Cap Adapter accommodate tertiary cap removal for the refueling task. The MFT also interfaces with the T-Valve Adapter, the Ambient Cap Adapter, and the Plug Manipulator Adapter to manipulate the demonstration features on the CVP. Figure 10 shows the MFT with its four corresponding adapters.

The SCT is designed to manipulate and remove the safety caps from the spacecraft fill/drain valves during refueling operations.

Finally, the ENT is designed to open/close the valve and transfer the simulated propellant across the fill/drain valve interface. A flexible hose connects the ENT to the FTS via the flexible hose management system (FHMS).

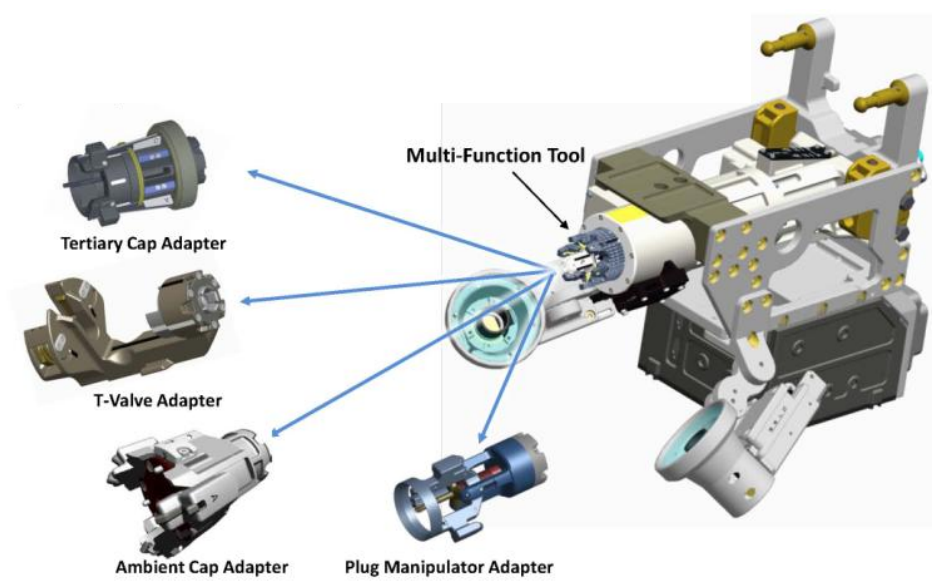

Figure 10. Typical Spacecraft Fill/Drain Valve Components The FHMS restrains the flexible hose and uses a system of pulleys and springs to allow the ENT and flexible hose to be removed from the tool stowage bench and installed onto the FTS plumbed valve. After the refueling fluid flow is complete, the ENT is removed from the plumbed fill/drain valve and the FHMS retracts the flexible hose as the ENT is restowed in the tool stowage bench. Figure 11 shows the WCT, SCT, and ENT while Figure 12 shows the major components of the FHMS.

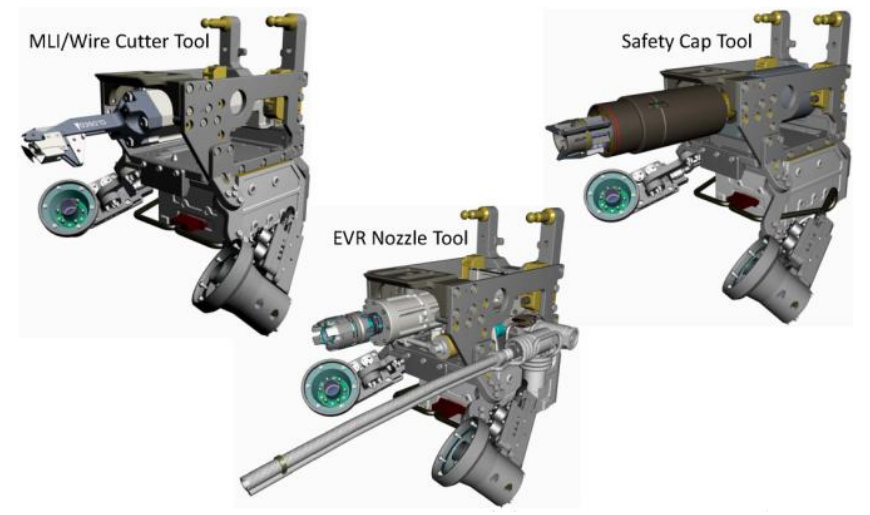

Figure 11. WCT, SCT, and ENT

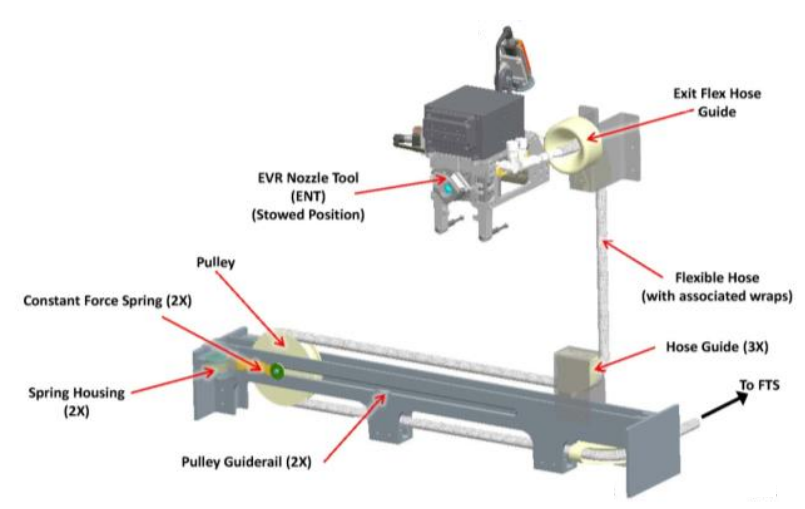

Figure 12. Flex Hose Management System

\section{Thermal Environments}

Table 1 lists the induced thermal environments on ISS. As this table shows, the ISS beta angle ranges $\pm 75^{\circ}$ with any combination of roll, pitch and yaw. In order to determine the worst case attitude for the RRM thermal analyses on ISS, the entire ISS flight envelope was studied. Black $(\mathrm{a} / \mathrm{e}=1)$ and white beta cloth $(\mathrm{a} / \mathrm{e}=0.55 / 0.88)$ unit spheres were placed at the ELC4 and EOTP locations and analyzed over the entire range of
Table 1: ISS Thermal Environment Parameters

\begin{tabular}{|c|c|}
\hline Configuration & Parameters \\
\hline Beta Angle & $\pm 75^{\circ}$ \\
\hline ISS Attitude & Any Combination of \\
Envelope & $\pm 15^{\circ}$ Roll (About $X$ axis) \\
$\pm 15^{\circ}$ Yaw (About $Z$ axis) \\
Without Orbiter & $+15^{\circ}$ to $-20^{\circ}$ Pitch (About $Y$ axis) \\
\hline
\end{tabular}

American Institute of Aeronauucs anu Asuonauucs 
ISS roll, pitch, and yaw combinations to determine sink temperatures and to trend the worst cases. The worst case hot and cold ISS attitude configurations were then used with worst case solar, albedo, and Earth IR constants to bound the RRM thermal design. Figure 13 shows the results of the ISS sink calculations.

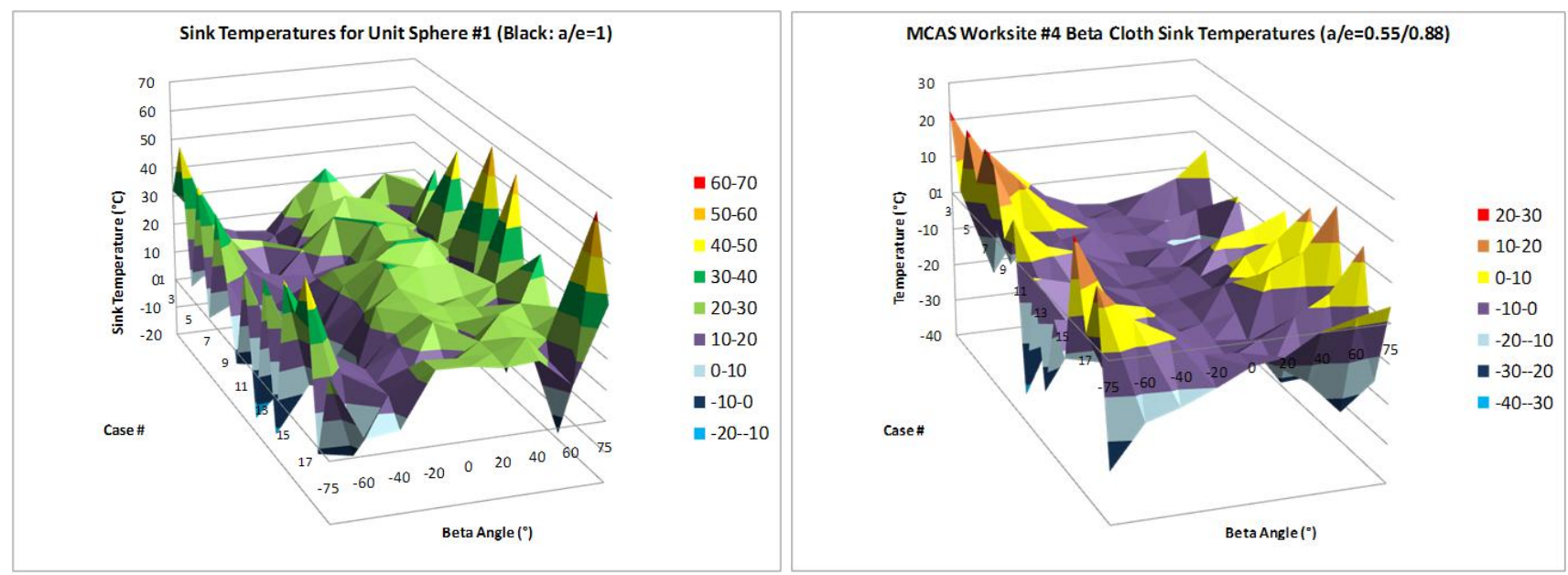

Figure 13. Unit Sphere Sink Temperature vs. Beta Angle\&Roll, Pitch, and Yaw Angle Plots

The RRM ISS thermal analyses were then executed with the detailed RRM model integrated into the ISS model, as shown in Figure 14, under the worst case hot/cold beta angle and ISS roll, pitch and yaw attitudes.

Thermal analyses of RRM in the space shuttle payload bay were executed over beta angles $\pm 60^{\circ}$ due to a launch constraint limiting the maximum allowable beta angle when docked with the ISS. In this case, the hot/cold analyses were executed to steady state conditions with the orbiter in a nominal bay to Earth attitude at worst case beta angles and solar, albedo, and Earth IR constants. The bay to Earth steady state temperatures are then used as the initial conditions for the final worst case hot and cold analyses. The worst case hot analysis starts with a hot bay to Earth attitude followed by 1.5 hours of bay to Sun. Similarly, the worst case cold analysis begins with a cold bay to Earth attitude followed by 1.5 hours of bay to space.

In each of the space shuttle analyses, the detailed RRM thermal math model was integrated onto the Lightweight Multi-Purpose Experiment Support Structure Carrier
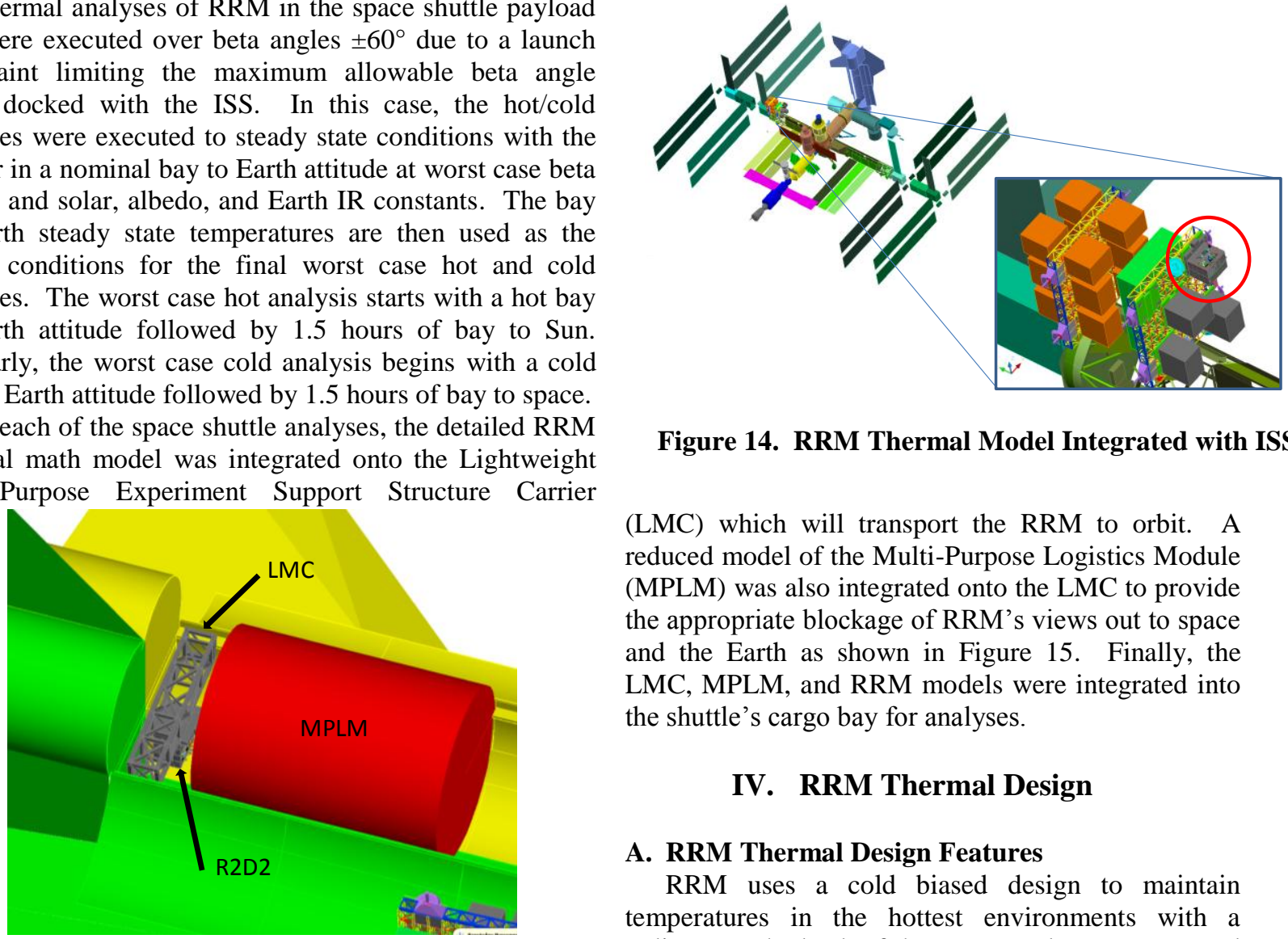

Figure 14. RRM Thermal Model Integrated with ISS

(LMC) which will transport the RRM to orbit. A reduced model of the Multi-Purpose Logistics Module (MPLM) was also integrated onto the LMC to provide the appropriate blockage of RRM's views out to space and the Earth as shown in Figure 15. Finally, the LMC, MPLM, and RRM models were integrated into the shuttle's cargo bay for analyses.

\section{RRM Thermal Design}

\section{A. RRM Thermal Design Features}

RRM uses a cold biased design to maintain temperatures in the hottest environments with a radiator on the back of the RRM enclosure. MLI and

Figure 15. RRM in the Space Shuttle Payload Bay

American Institute of Aeronautics and Astronautics 
heaters are used to maintain component temperatures in worst case cold environments.

RRM is conductively isolated from the ELC via the Active to Passive Flight Releasable Attachment Mechanism (FRAM) interface. With the exception of the RRM radiator, all sides of the RRM enclosure are covered with MLI and a white beta cloth external layer. The task boards, CVP, and receptacles are thermally isolated from the RRM enclosure with G-10 and Ultem-1000 spacers to reduce heat leaks into the RRM. Similarly, the back of the FTS plate and the FHMS are covered with Ag Teflon MLI to minimize solar loading through the tool stowage compartment opening. The TVSS, cameras, and TEBs are covered with Ag Teflon tape and the camera LED housings are painted with white Z-93.

For the FTS, the plumbed fill/drain valves are coupled to the enclosure with eGraf ${ }^{\circledR}$ thermal gaskets to dissipate the heat produced when the valves are activated. The ACU, pump controller, pumps, and valves are also coupled to the FTS plate with eGrafß thermal gaskets.

\section{B. RRM Heater Design}

RRM utilizes three separate sets of heaters as follows, depending on the location and operation of the hardware: (1) $28 \mathrm{~V}$ heaters powered through the space shuttle, (2) $120 \mathrm{~V}$ heaters powered through the ISS, and (3) $15 \mathrm{~V}$ heaters powered through the OTCM.

While RRM is in the space shuttle cargo bay, the LMC powers 4 circuits of heaters located on the FTS plate for a total allocation of $230 \mathrm{~W}$ at maximum voltage. At nominal voltage the space shuttle heaters provide approximately 216W. Each circuit of the shuttle heaters are controlled by two Elmwood mechanical thermostats wired in series to automatically control the heater on/off temperatures between $+25^{\circ} \mathrm{C}$ and $+30^{\circ} \mathrm{C}$.

When RRM is installed on the ELC4, the ISS provides two heaters feeds for a total allocation of $290 \mathrm{~W}$ at maximum voltage or approximately $245 \mathrm{~W}$ at nominal voltage. The ISS heaters are located on the FTS plate, on the fluid flex line, and on the RRM enclosure next to the plumbed fill/drain valves. Each of the ISS heater circuits are controlled with mechanical thermostats wired in series. The FTS plate and plumbed fill/drain valve thermostats have close/open set points of $+5^{\circ} / 11^{\circ} \mathrm{C}$. The primary and secondary flex hose heater set points are offset by $5^{\circ} \mathrm{C}$ to reduce heater watt density. The primary flex hose heater circuit has thermostat set points of $+10^{\circ} \mathrm{C} /+16^{\circ} \mathrm{C}$ while the secondary flex hose heater circuit has a range of $+5^{\circ} \mathrm{C} /+11^{\circ} \mathrm{C}$. When RRM is installed on the EOTP, only one of the two ISS power feeds are available. Figure 16 shows the location of the shuttle and ISS heaters and their corresponding thermostats on the FTS plate.

For robotic refueling or tool operation, the OTCM

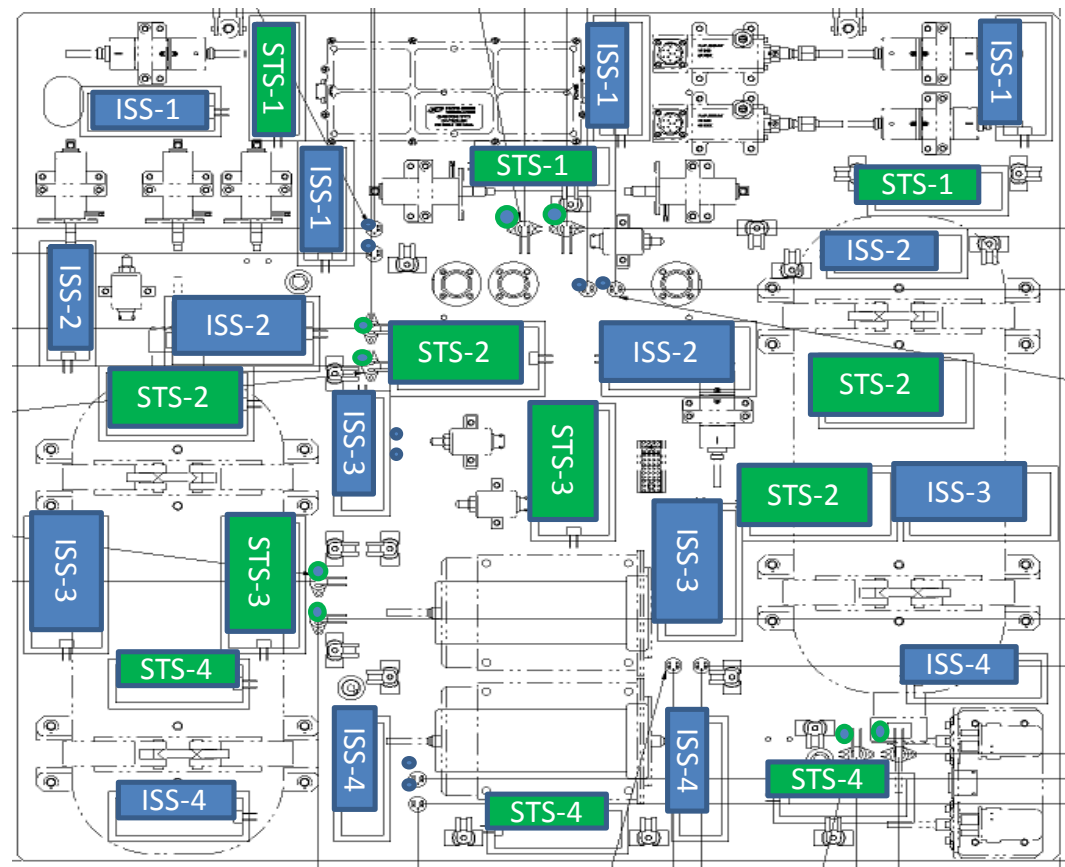

- Thermostats

powers heaters on the tool cameras and TEBs. Each camera has a $5 \mathrm{~W}$ nominal voltage heater for a total of two per tool and the TEB has a 10W nominal voltage heater for a total of one per tool. The camera thermostats have set points of $-25^{\circ} \mathrm{C} /-16^{\circ} \mathrm{C}$ while the TEB heater range is $-32^{\circ} \mathrm{C} /-26^{\circ} \mathrm{C}$. These heaters are only powered through the OTCM so no tool heater power is available when the tools are stowed on the tool stowage bench inside the RRM enclosure. 


\section{RRM Power Dissipations}

Table 2 shows the worst case power dissipations assigned to the RRM hot case thermal analyses. FTS component dissipation during hot case fluid transport operations are assumed to have a duration of 5 minutes. For conservatism, the cold case analyses assume no FTS power dissipation and minimum dissipations on the deployed tools and tool electronics. The tool and tool electronic dissipations are only applied when the tool is deployed for operation.

Table 2: RRM Power Dissipation

\begin{tabular}{|c|c|c|c|c|c|}
\hline Component & $\begin{array}{l}\text { Total } \\
\text { Qty }\end{array}$ & $\begin{array}{l}\text { Min Power } \\
\text { Dissipation } \\
\text { (W) }\end{array}$ & $\begin{array}{l}\text { Power } \\
\text { Dissipation } \\
\text { (W) }\end{array}$ & $\begin{array}{l}\text { Operate } \\
\text { Duration }\end{array}$ & Comments \\
\hline $\mathrm{ACU}$ & 1 & 0 & $30 \mathrm{~W}$ & $5 \mathrm{~min}$ & \\
\hline Valves & 6 & 0 & $27.9 \mathrm{~W}$ & $5 \mathrm{~min}$ & $\begin{array}{l}\text { Per valve power } \\
\text { dissipation (Max of } 4 \text { on at } \\
\text { a time) }\end{array}$ \\
\hline Pump Controller & 1 & 0 & $4.26 \mathrm{~W}$ & $5 \mathrm{~min}$ & 20W @ start-up for 1 sec. \\
\hline Pump & 2 & 0 & $10 \mathrm{~W}$ & $5 \mathrm{~min}$ & $\begin{array}{l}\text { Operated } 1 \text { at a time. Up } \\
\text { to } 30 \mathrm{~W} \text { dissipated with } \\
2 / 3 \text { of the energy removed } \\
\text { through flowing ethanol }\end{array}$ \\
\hline TEB (1) per tool & 4 & $2.5 \mathrm{~W}$ & 3.8W Hot & $\begin{array}{l}\text { Extended } \\
\text { Duration }\end{array}$ & \\
\hline Camera s (2) per tool & 8 & $2.04 \mathrm{~W}$ & $\begin{array}{l}2.76 \mathrm{~W} \\
\text { each }\end{array}$ & $\begin{array}{l}\text { Extended } \\
\text { Duration }\end{array}$ & 2 Cameras per tool \\
\hline $\begin{array}{l}\text { Camera Diodes (LED's) } \\
\text { (6) per camera }\end{array}$ & 48 & $0.05 \mathrm{~W}$ & $\begin{array}{l}0.067 \mathrm{~W} \\
\text { each }\end{array}$ & $\begin{array}{l}\text { Extended } \\
\text { Duration }\end{array}$ & $\begin{array}{l}2 \text { cameras } x 6 \text { diodes }=12 \\
\text { diodes per tool }\end{array}$ \\
\hline
\end{tabular}

\section{RRM Thermal Analyses Results}

The RRM thermal math model was exercised over the worst case environments and power dissipations as detailed above to determine the operating and non-operating temperature ranges for the hardware. Due to the extreme environmental conditions at high beta angles, RRM operational cases, including tool deployment and FTS functions, will only be considered for beta angles $\leq 60^{\circ}$. ISS documentation will include a flight rule constraint prohibiting RRM operation above $60^{\circ}$ beta angles. The RRM hot non-operate case assumes the $75^{\circ}$ maximum ISS beta angle. Table 3 summarizes the major RRM component temperatures while the RRM is installed onto ELC4.

While stowed on the LMC in the space shuttle cargo bay, RRM remains in a non-operate mode with only the shuttle FTS plate heaters powered. A space shuttle flight rule restricts launch at beta angles $>60^{\circ}$, therefore the hot shuttle case assumes a $60^{\circ}$ beta angle while the cold case assumes a $0^{\circ}$ beta angle. As stated previously, the shuttle cases assume cold or hot bay to Earth steady state conditions followed by 1.5 hours of bay to space for the worst case cold conditions and 1.5 hours of bay to Sun for the worst case hot conditions. Table 4 summarizes the major RRM component temperatures while in the shuttle cargo bay following the 1.5 hours of worst case shuttle attitude.

\section{Conclusion}

The RRM thermal design has been shown to maintain all components above their hot and cold temperature limits for all operational and non-operational scenarios over the entire flight envelope of the ISS. In addition, the RRM remains within its non-operate temperature limits under worst case hot bay to Sun and cold bay to space attitudes while installed on the LMC in the shuttle cargo bay. 
Table 3: RRM Thermal Predictions on ISS

\begin{tabular}{|c|c|c|c|c|c|c|c|c|}
\hline \multirow{2}{*}{ Component } & \multicolumn{8}{|c|}{ RRM Installed on ISS ELC4 } \\
\hline & $\begin{array}{l}\text { Cold Non-Op } \\
\text { Limit }\left({ }^{\circ} \mathrm{C}\right)\end{array}$ & $\begin{array}{l}\text { Cold Non-Op* } \\
\left({ }^{\circ} \mathrm{C}\right) \text { : Qhtr }(\mathrm{W})\end{array}$ & $\begin{array}{l}\text { Cold Op } \\
\text { Limit }\left({ }^{\circ} \mathrm{C}\right)\end{array}$ & $\begin{array}{l}\text { Cold Op** } \\
\qquad\left({ }^{\circ} \mathrm{C}\right)\end{array}$ & $\begin{array}{c}\text { Hot Op } \\
\text { Limit }\left({ }^{\circ} \mathrm{C}\right)\end{array}$ & $\begin{array}{c}\text { Hot Op** } \\
\left({ }^{\circ} \mathrm{C}\right)\end{array}$ & \begin{tabular}{||l} 
Hot Non-Op \\
Limit $\left({ }^{\circ} \mathrm{C}\right)$
\end{tabular} & $\begin{array}{c}\text { Hot Non-Op* } \\
\left({ }^{\circ} \mathrm{C}\right)\end{array}$ \\
\hline FTS Plate & -40 & $\begin{array}{c}-15 \\
\text { Qhtr=123W (67\%) } \\
\end{array}$ & -7 & $\begin{array}{c}-1 \\
\text { Qhtr }=118 \mathrm{~W}(64 \%) \\
\end{array}$ & 50 & 43 & 65 & 60 \\
\hline FTS Valves & -40 & 5 & -7 & 5 & 149 & 120 & 149 & 60 \\
\hline Flex Hose & -48 & $\begin{array}{c}10 \\
\text { Qhtr }=2.4 \mathrm{~W}(53 \%) \\
\end{array}$ & 0 & $\begin{array}{c}10 \\
\text { Qhtr }=3.1 \mathrm{~W}(52 \%) \\
\end{array}$ & 80 & 32 & 80 & 67 \\
\hline Plumbed Fill/Drain Valves & -50 & $\begin{array}{c}-1 \\
\text { Qhtr }=22 \mathrm{~W}(40 \%) \\
\end{array}$ & -15 & $\begin{array}{c}4 \\
\text { Qhtr }=25 \mathrm{~W}(50 \%) \\
\end{array}$ & 60 & 42 & 105 & 81 \\
\hline Task Boards \& CVP & -75 & -62 & -75 & -62 & 95 & 70 & 125 & 121 \\
\hline CVP T Valves & -85 & -46 & -75 & -48 & 126 & 120 & 232 & 205 \\
\hline CVP Ambient Valves & -85 & -30 & -75 & -28 & 126 & 77 & 150 & 121 \\
\hline WCT & -65 & -16 & -46 & -14 & 80 & 26 & 90 & 72 \\
\hline SCT & -70 & -16 & -70 & -14 & 78 & 26 & 83 & 72 \\
\hline MFT & -60 & -16 & -60 & -32 & 80 & 68 & 80 & 72 \\
\hline ENT & -45 & -16 & -45 & -32 & 95 & 66 & 95 & 72 \\
\hline TEBs & -52 & -17 & -37 & $\begin{array}{c}-30 \\
\text { Qhtr }=1.7 \mathrm{~W}(17 \%)\end{array}$ & 68 & 45 & 86 & 71 \\
\hline Cameras & -49 & -15 & -31 & $\begin{array}{c}-20 \\
\text { Qhtr }=2.3 \mathrm{~W}(23 \%) \\
\end{array}$ & 72 & 54 & 86 & 71 \\
\hline Diodes (LEDs) & -49 & -15 & -31 & -10 & 82 & 64 & 86 & 71 \\
\hline
\end{tabular}

* Cold and Hot Non-Op cases have all tools stowed in the tool stowage bench with no heater power.

** Cold and Hot Op cases have the MFT and ENT deployed and operating. The WCT and SCT are stowed in the tool stowage bench. 
Table 4: RRM Thermal Predictions in the Space Shuttle

\begin{tabular}{|c|c|c|c|c|}
\hline \multirow{2}{*}{ Component } & \multicolumn{4}{|c|}{ RRM Installed on LMC in the Shuttle Cargo Bay } \\
\hline & $\begin{array}{l}\text { Cold Non-Op } \\
\text { Limit }\left({ }^{\circ} \mathrm{C}\right)\end{array}$ & $\begin{array}{l}\text { Cold Non-Op } \\
\left({ }^{\circ} \mathrm{C}\right): \operatorname{Qhtr}(\mathrm{W})\end{array}$ & $\begin{array}{l}\text { Hot Non-Op } \\
\text { Limit }\left({ }^{\circ} \mathrm{C}\right)\end{array}$ & $\begin{array}{c}\text { Hot Non-Op } \\
\left({ }^{\circ} \mathrm{C}\right)\end{array}$ \\
\hline FTS Plate & -40 & $\begin{array}{c}13 \\
\text { Qhtr }=167 \mathrm{~W}(80 \%) \\
\end{array}$ & 65 & 38 \\
\hline FTS Valves & -40 & 20 & 149 & 27 \\
\hline Flex Hose & -48 & -12 & 80 & 37 \\
\hline Plumbed Fill/Drain Valves & -50 & -20 & 105 & 74 \\
\hline Task Boards \& CVP & -75 & -30 & 125 & 85 \\
\hline CVP T Valves & -85 & -48 & 232 & 121 \\
\hline CVP Ambient Valves & -85 & -28 & 150 & 88 \\
\hline WCT & -65 & -18 & 90 & 55 \\
\hline SCT & -70 & -18 & 83 & 55 \\
\hline MFT & -60 & -18 & 80 & 55 \\
\hline ENT & -45 & -18 & 95 & 55 \\
\hline TEBs & -52 & -19 & 86 & 60 \\
\hline Cameras & -49 & -16 & 86 & 52 \\
\hline Diodes (LEDs) & -49 & -16 & 86 & 52 \\
\hline
\end{tabular}




\section{Appendix}

Below are a list of the acronyms used in this report.

$\begin{array}{ll}\text { ACU } & \text { Avionics Control Unit } \\ \text { CVP } & \text { Coolant Valve Panel } \\ \text { ELC4 } & \text { Express Logistics Carrier } 4 \\ \text { ENT } & \text { EVR Nozzle Tool } \\ \text { EOTP } & \text { Enhanced ORU Temporary Platform } \\ \text { EVA } & \text { Extra Vehicular Activity } \\ \text { EVR } & \text { Extra Vehicular Robotic } \\ \text { ExPA } & \text { Express Adapter Plate } \\ \text { FHMS } & \text { Flex Hose Management System } \\ \text { FTS } & \text { Fluid Transfer System } \\ \text { ISS } & \text { International Space Station } \\ \text { LMC } & \text { Lightweight Multi-Purpose Experiment Support Structure } \\ \text { MFT } & \text { Multi-Function Tool } \\ \text { MLI } & \text { Multi-Layer Insulation } \\ \text { MPLM } & \text { Multi-Purpose Logistics Module } \\ \text { ORU } & \text { Orbital Replacement Unit } \\ \text { OTCM } & \text { ORU/Tool Changeout Mechanism } \\ \text { RRM } & \text { Robotic Refueling Mission } \\ \text { SCT } & \text { Safety Cap Tool } \\ \text { SPDM } & \text { Special Purpose Dexterous Manipulator } \\ \text { SSRMS } & \text { Space Station Remote Manipulator System } \\ \text { TEB } & \text { Tool Electronics Box } \\ \text { TVSS } & \text { Tool and Vision Support Structure } \\ \text { WCT } & \text { Wire Cutter Tool } \\ & \end{array}$

\section{Acknowledgments}

The authors would like to acknowledge and thank Michael Lajczok of ATK Space for his hard work and dedication in helping the RRM thermal team to meet the many demanding technical and schedule challenges during the design and development of RRM. 